\title{
EFFECT OF FULVIC AND HUMIC ACIDS ON IRON AND MANGANESE HOMEOSTASIS IN RATS
}

\author{
József SzABÓ $^{1 *}$, András Valentin VuCSKITS ${ }^{2}$, Erzsébet BERTA ${ }^{1}$, Emese ANDRÁSOFSZKY $^{1}$, \\ András BERSÉNYI ${ }^{1}$ and István HULLÁR ${ }^{1}$ \\ ${ }^{1}$ Department of Animal Breeding, Nutrition and Laboratory Animal Science, University \\ of Veterinary Medicine, P. O. Box 2, H-1400 Budapest, Hungary; ${ }^{2}$ Europharmavet Ltd., \\ Budapest, Hungary
}

(Received 4 October 2016; accepted 6 January 2017)

The objective of this study was to investigate the effects of fulvic acid (FA) and humic acid (HA) as the two main compounds of humic substances, separately on Fe and Mn homeostasis. Seventy-two male Wistar rats were randomly divided into 9 experimental groups. The control diet (AIN-93G formula) and diets supplemented with $0.1 \%, 0.2 \%, 0.4 \%$ and $0.8 \%$ HA or FA were fed for 26 days. Fe and Mn concentrations of the large intestinal content, liver, kidney, femur and hair were determined. No significant differences were observed in the production parameters. The effects of FA and HA on iron homeostasis were significantly different. FA proved to be a good iron source, and slightly increased the iron content of liver and kidney, but - up to a dietary iron level of $52.7 \mathrm{mg} / \mathrm{kg}$ - it did not influence the efficiency of iron absorption. Above a dietary iron level of $52.7 \mathrm{mg} / \mathrm{kg}$ down-regulation of Fe absorption can be assumed. HA significantly stimulated the iron uptake and there was no down-regulation of Fe absorption up to $0.8 \%$ dietary HA supplementation level $(61.5 \mathrm{mg} \mathrm{Fe} / \mathrm{kg}$ diet $)$. In the HA groups the iron content of the liver and kidney decreased significantly, suggesting that in spite of the better Fe absorption, the HA-Fe complex does not provide iron to the investigated organs. Neither FA nor HA supplementation influenced the Fe content of the femur and hair and slightly decreased the Mn concentration in the large intestinal content. This effect was significant (with a $22.7 \% \mathrm{Mn}$ concentration decrease) only at the HA supplementation rate of $0.8 \%$. Neither FA nor HA influenced significantly the Mn concentrations of the liver, kidney and femur. The Mn concentration of the hair in rats receiving FA- or HA-supplemented diets was higher than in the control rats; however, this result needs further confirmation.

Key words: Fulvic acid, humic acid, trace element metabolism, iron, manganese, homeostasis

Recently, humic substances (HSs) have been widely used in animal nutrition to improve the profitability of animal production and the health status of

*Corresponding author; E-mail: szabo.jozsef@univet.hu; Phone: 0036 (1) 478-4126; Fax: 0036 (1) 478-4124 
animals, and they are regarded as possible alternatives to antibiotic growth promoters that have been phased out in line with the relevant EU legislation since the end of 2005.

HSs include humus, humic acid, fulvic acid, ulmic acid, and trace minerals, which are necessary for plant development (Stevenson, 1994; Herzig et al., 2009). The two most active fractions of HSs are humic acid (HA) and fulvic acid (FA). HA has a medium molecular weight around 5,000-100,000 Daltons. FA has the lowest molecular weight, around 2000 Daltons (Islam et al., 2005). Humic acids have been shown to exert various effects through their chemical structure, the heterogeneous functional groups, their adsorption capacity and complex-forming ability (Madronova et al., 2001).

Although HSs can combine with metal ions, oxides and clay to form water-soluble or insoluble complexes and can interact with organic compounds (Boyd et al., 1981; Livens, 1991; Islam et al., 2005), only a few studies have investigated the specific effects of FA or HA on the intestinal absorption of trace elements (Willis, 2015) and on the trace element concentrations in different organs of piglets (Zraly and Pisarikova, 2010) and rats (Cagin et al., 2016).

It seems that the discrepancies found in the literature regarding the effects of HSs on the production traits of poultry (Bailey et al., 1996; Parks, 1998; Kocabagli et al., 2002; Mevlüt et al., 2004) and piglets (Schuhmacher and Gropp, 2000; Kaya and Tuncer, 2009) might be due to differences in the composition of HSs. Such differences emphasise the care that must be used when drawing conclusions from data collected by different researchers, using different HSs. Thus, it is imperative to characterise HSs and highlight the importance of further delineating the effects of the two main compounds (FA and HA) of HSs individually.

The question arises as to how HSs influence the mineral homeostasis of animals when used as potential growth promoters. The objective of this study was to investigate the effects of FA and HA separately, on the concentration of $\mathrm{Fe}$ and $\mathrm{Mn}$ in the large intestinal contents (which roughly gives an indirect picture about the absorption of the trace elements), and also on the trace element concentrations in the liver, kidney, femur, and hair of rats.

\section{Materials and methods}

Animals

Seventy-two weaned, Wistar CRL:(WI) BR, male, SPF rats were used in this experiment. Animals were housed in individual cages at $24{ }^{\circ} \mathrm{C}$ ambient temperature. After 4 days adaptation the animals were divided into 9 dietary treatment groups on the basis of their body weight, which was balanced among the treatment groups. One control and 8 treatment groups were set up. The control diet was prepared according to the AIN-93G formula of the American Institute of 
Nutrition (Reeves, 1997). The experimental diets were prepared by supplementation of the control diet with $0.1 \%, 0.2 \%, 0.4 \%$, and $0.8 \%$ of FA or HA in place of starch. The diets were fed for 26 days. Water and feed were provided ad libitum during the experiment.

\section{HS fractionation}

Both FA and HA were donated by ORGANIT Ltd. (Veszprém, Hungary). FA and HA were extracted from leonardite [a soft waxy, black and brown, shiny vitreous mineraloid easily soluble in alkaline solution; it is an oxidation product of lignite, associated with near-surface mining (Neuendorf et al., 2011)] briefly as follows: the leonardite powder $(10 \%)$ was dissolved in $2 \% \mathrm{NaOH}$ solution at $60{ }^{\circ} \mathrm{C}$ for $2 \mathrm{~h}$ and was oxidised with $3 \%$ hydrogen peroxide. After this extraction the supernatant was treated with $\mathrm{HCl}(5 \%)$. In this process the HA fraction precipitates, while the FA fraction remains in the supernatant. For the purification of FA from non-humic materials (amino acids, peptides, sugars, etc.) resin column separation was used. At low $\mathrm{pH}$ the FA adsorbs on the resin, but non-humic materials pass through the column. With the above-mentioned standardised process chemically pure HA and FA can be produced without any contamination (heavy metals, amino acids, sugars, etc.).

\section{Measurements and analysis}

Body weight (BW) and feed consumption were measured three times a week. On day 26 of the trial all of the rats were narcotised $(90 \mathrm{mg} / \mathrm{kg} \mathrm{BW} \mathrm{CP}$ ketamine and $0.5 \mathrm{mg} / \mathrm{kg} \mathrm{BW}$ medetomidine) and exsanguinated. Samples of large intestinal (caecum + colon) content, liver, kidney, femur and hair were collected and stored at $-20{ }^{\circ} \mathrm{C}$ until further examinations.

The sample preparation procedures were as follows. The liver and kidney samples and the large intestinal content were dried at $60^{\circ} \mathrm{C}$ for two days, crushed by mortar, homogenised and microwave-digested (Milestone MLS 1200) with $65 \%$ nitric acid. Femur samples were cleaned of non-osseous tissue, dried at $60{ }^{\circ} \mathrm{C}$, then ashed at $550{ }^{\circ} \mathrm{C}$ for at least $48 \mathrm{~h}$.

Hair samples were washed with a solution of $1 \%$ sodium lauryl sulphate, washed repeatedly with deionised water, dried and then ashed at $550{ }^{\circ} \mathrm{C}$ overnight. The ashes were then dissolved in $6 \mathrm{M}$ hydrochloric acid. Fe and Mn concentrations were determined by a Carl Zeiss Jena AAS3 atomic absorption spectrometer. In case of hair samples, because of low collectible quantities per animal, identical quantities were collected from each animal and pooled into treatment groups.

The results are expressed as means $\pm \mathrm{SD}$. Statistical analysis of data was performed by one-way analysis of variance (ANOVA) with Tukey's post-hoc multiple comparison test. Response curves were fitted by linear and quadratic regression procedures using MS Excel 2003 software. 
The experimental protocol met the standard criteria of the Scientific Ethics Committee of Animal Experiments of the University of Veterinary Medicine, Budapest, Hungary.

\section{Results and discussion}

\section{Effects of FA and HA on the trace element concentrations of diets}

As Table 1 indicates, both FA and HA are very rich in iron. This means that even a low level of FA or HA supplementation significantly increased the Fe content of the diets. From the point of view of the Fe and $\mathrm{Mn}$ requirements of the rats (Fe: 35 and $\mathrm{Mn}: 50 \mathrm{mg} / \mathrm{kg}$ diet; NRC, 1995) only the increase of Fe concentration of the diets can be regarded as significant (at $0.8 \%$ supplementation with FA and HA $53.3 \%$ and $47.7 \%$, respectively). The increased concentrations of $\mathrm{Fe}$ may influence both the absorption rate of $\mathrm{Fe}$ from the rat intestine and the $\mathrm{Fe}$ content of the organs. The chelating ability of FA and HA may also influence the trace element homeostasis of the animals.

\section{Table 1}

Iron and manganese concentrations of fulvic acid (FA), humic acid (HA) and of the experimental diets

\begin{tabular}{|c|c|c|c|c|c|c|}
\hline & & FA & HA & & & \\
\hline $\mathrm{Fe}$ & $\mathrm{mg} / \mathrm{kg}$ & 2774 & 2483 & & & \\
\hline \multirow[t]{2}{*}{$\mathrm{Mn}$} & $\mathrm{mg} / \mathrm{kg}$ & 48.2 & 8.63 & & & \\
\hline & & \multicolumn{5}{|c|}{$\mathrm{Fe}$ and $\mathrm{Mn}$ concentrations of FA-supplemented diets } \\
\hline FA & $\%$ of diet & 0.0 & 0.1 & 0.2 & 0.4 & 0.8 \\
\hline \multirow[t]{2}{*}{$\mathrm{Fe}$} & $\mathrm{mg} / \mathrm{kg}$ diet & 41.6 & 44.4 & 47.2 & 52.7 & 63.8 \\
\hline & $\%$ & 100.0 & 106.7 & 113.3 & 126.7 & 153.3 \\
\hline \multirow[t]{3}{*}{$\mathrm{Mn}$} & $\mathrm{mg} / \mathrm{kg}$ diet & 11.0 & 11.1 & 11.1 & 11.2 & 11.4 \\
\hline & $\%$ & 100.0 & 100.5 & 100.9 & 101.7 & 103.6 \\
\hline & & \multicolumn{5}{|c|}{$\mathrm{Fe}$ and $\mathrm{Mn}$ concentrations of HA-supplemented diets } \\
\hline HA & $\%$ of diet & 0.0 & 0.1 & 0.2 & 0.4 & 0.8 \\
\hline \multirow[t]{2}{*}{$\mathrm{Fe}$} & $\mathrm{mg} / \mathrm{kg}$ & 41.6 & 44.1 & 46.6 & 51.5 & 61.5 \\
\hline & $\%$ & 100.0 & 106.0 & 112.0 & 123.9 & 147.7 \\
\hline \multirow[t]{2}{*}{$\mathrm{Mn}$} & $\mathrm{mg} / \mathrm{kg}$ & 11.0 & 11.0 & 11.0 & 11.0 & 11.1 \\
\hline & $\%$ & 100.0 & 100.1 & 100.2 & 100.3 & 100.6 \\
\hline
\end{tabular}




\section{Effects of FA and HA on production}

Compared to the control rats, none of the supplemental doses of FA or HA influenced the production parameters of the rats significantly (this was also true with pooled data analysis of different treatment groups) (feed intake: control $6.54 \pm 0.19$, FA $6.53 \pm 0.43$, HA $6.60 \pm 0.33 \mathrm{~g} / 100 \mathrm{~g}$ BW; body weight gain: control $2.16 \pm 0.19$, FA $2.10 \pm 0.14$, HA $2.16 \pm 0.15 \mathrm{~g} / 100 \mathrm{~g} \mathrm{BW}$; feed/gain ratio: control $3.02 \pm 0.32$, FA $3.13 \pm 0.34$, HA $3.07 \pm 0.32 \mathrm{~g} / \mathrm{g}$ ).

Regarding the production parameters, the data available in the literature are contradictory. Our results showing no significant feed intake or body weight changes are in accordance with the data of Schuhmacher and Gropp (2000) in weaning pigs and with those of Mevlüt et al. (2004) and Kaya and Tuncer (2009) in broilers.

Contrary to these reports, when Menefee ${ }^{\circledR}$ Humate (containing 60\% HA and $26 \%$ FA) was fed to poultry, significantly increased body weight gain and feed/ gain ratio were observed (Bailey et al., 1996; Parks, 1998; Kocabagli et al., 2002).

Concerns have been raised regarding the possible adverse effect(s) of the high iron content of HSs on the production traits. Fischer et al. (2002) suggested that up to $1500 \mathrm{mg} / \mathrm{kg}$ BW HSs had no adverse effects on the growth rate of rats. Yeung et al. (2005) also reported that a high concentration of NaFeEDTA, also a chelated form of iron, had no effects on the body weights of rats and was not toxic, likely due to the down-regulation of intestinal iron absorption.

Although the mechanism of the assumed growth promoting effect of HSs is not completely understood, Kocabagli et al. (2002) hypothesised that HSs might increase the intestinal uptake of nitrogen, phosphorus and other nutrients due to their chelating properties. The factors behind the published discrepancies relating to the growth promoting effects of HSs might be the different composition (FA/HA ratio) of humic products (Kocabagli et al., 2002) on the market and/or the animal species used.

\section{Effects of FA and HA on trace element concentrations of the large intestinal content, liver, kidney, bone and hair}

When evaluating the effects of FA and HA supplementation on the trace element homeostasis, two factors must be taken into consideration, namely the effect of their mineral content and their effects as biologically active substances. We assumed that the dose-related differences between the mineral concentration changes of the FA- or HA-supplemented diets and that of the large intestinal contents and the different organs may give direct (trace element concentrations of organs) and indirect (absorption) information about the specific effects of FA or HA on mineral absorption and homeostasis.

The prerequisite of the veracity of this assumption is that there are no significant differences in the digestibility of the organic matter of the experimental 
diets between the control and treatment groups. In our experiment the organic components of the diets were identical, and the feed intake, body weight gain and the feed/gain ratio did not differ significantly from the control values.

Iron

Iron is an essential trace element, which is necessary for different biological functions including oxygen transport, mitochondrial electron transfer, and several enzymatic reactions. It can be toxic, and excess iron may increase the formation of oxygen free radicals. Consequently, the iron homeostasis must be strictly regulated to prevent the accumulation of toxic quantities in the organisms. It is believed that the iron homeostasis is regulated at the level of absorption by the proximal small intestine (Miret et al., 2003). However, Takeuchi et al. (2005) reported that in iron-deficient mice there was a significant level of expression of the iron absorption genes Iregl and DMT1 in the caecum and in the proximal and distal colon.

As Morgan and Oates (2002) summarised, iron absorption from the small intestine is regulated according to the body's needs, increasing in iron deficiency and decreasing in iron overload. It has been proposed that the efficiency of absorption is determined by the amount of iron acquired by developing enterocytes when they are in the crypts of Lieberkühn and that this regulates the expression of iron transporters such as DMT1 in mature enterocytes of the intestinal villi. In the crypts the cells take up iron from plasma transferrin by receptor-mediated endocytosis, a process that is influenced by the haemochromatosis protein (also known as HFE protein). Hence, the availability of plasma transferrin-bound iron and the expression and function of transferrin receptors (TfR1), HFE and DMT1 should all contribute to the absorptive capacity of villus enterocytes.

Although, in a mouse gut model, Willis (2015) demonstrated that both FA and HA significantly stimulated the intestinal absorption of iron, there are no data in the literature about the dose-related effect of pure FA and HA on trace element absorption in an in vivo model.

The data of our experiment (Table 1) show that both FA and HA supplementation increased the iron content of the diets substantially and in a dosedependent manner.

Feeding of the FA-supplemented diets increased the Fe concentration of the large intestinal content $(\mathrm{LIC})$ significantly $(\mathrm{P}<0.05)$ and in a dose-related manner $\left(\mathrm{R}^{2}=0.975\right)$ above the control value (Table 2 and Fig. 1$)$. This followed the relative iron concentration change of the diets up to $0.4 \%$ FA supplementation. At $0.8 \% \mathrm{FA}$, the relative increment of Fe concentration in LIC was $20 \%$ higher than its increase in the diet, suggesting that up to a dietary iron level of $52.7 \mathrm{mg} / \mathrm{kg}$ FA did not influence the efficiency of $\mathrm{Fe}$ absorption, probably due to the fact that because of the increased Fe supply, proportionally more iron was absorbed. Above these iron levels a down-regulation of intestinal absorption is likely (Fig. 1). 
Table 2

Effect of fulvic acid (FA) or humic acid (HA) on the iron concentration of the large intestinal content (LIC), liver, kidney, femur, and hair of rats ( $\mathrm{mg} / \mathrm{kg}$ dry matter)

\begin{tabular}{|c|c|c|c|c|c|}
\hline & \multicolumn{5}{|c|}{ FA ( $\%$ of diet $)$} \\
\hline & 0.0 & 0.1 & 0.2 & 0.4 & 0.8 \\
\hline LIC & $720.0 \pm 18.6^{\mathrm{a}}$ & $727.6 \pm 75.2^{\mathrm{a}}$ & $858.5 \pm 54.4^{\mathrm{b} \dagger}$ & $894.8 \pm 52.9^{\mathrm{b} \dagger}$ & $1247.0 \pm 175.8^{\mathrm{c} \dagger}$ \\
\hline Liver & $522.6 \pm 73.0$ & $582.2 \pm 110.2$ & $543.6 \pm 45.1$ & $588.7 \pm 41.0$ & $624.2 \pm 101.6$ \\
\hline Kidney & $263.6 \pm 9.1^{\mathrm{a}}$ & $306.2 \pm 23.9^{b}$ & $274.0 \pm 2.5^{\mathrm{b}}$ & $298,8 \pm 15.6^{\mathrm{b}}$ & $279.6 \pm 14.8^{b}$ \\
\hline Femur & $284.2 \pm 55.6$ & $284.8 \pm 59.3$ & $233.7 \pm 30.1$ & $285.0 \pm 11.4$ & $269.25 \pm 18.3$ \\
\hline \multirow[t]{3}{*}{ Hair $^{*}$} & 13.7 & 12.6 & 13.6 & 11.9 & 14.1 \\
\hline & \multicolumn{5}{|c|}{ HA ( $\%$ of diet) } \\
\hline & 0.0 & 0.1 & 0.2 & 0.4 & 0.8 \\
\hline LIC & $720.0 \pm 18.6^{\mathrm{a}}$ & $709.8 \pm 32.7^{\mathrm{a}}$ & $715.7 \pm 50.7^{\mathrm{a}^{\dagger}}$ & $723.0 \pm 40.3^{\mathrm{a}^{\dagger}}$ & $764.2 \pm 56.6^{\mathrm{a} \dagger}$ \\
\hline Liver & $522.6 \pm 73.0^{\mathrm{a}}$ & $496.4 \pm 80.2^{\mathrm{a}}$ & $358.2 \pm 62.3^{\mathrm{b}}$ & $395.2 \pm 28.1^{\mathrm{b}}$ & $402.6 \pm 40.6^{\mathrm{b}}$ \\
\hline Kidney & $263.6 \pm 9.1^{\mathrm{ab}}$ & $273.4 \pm 22.0^{\mathrm{a}}$ & $239.6 \pm 26.3^{b c}$ & $243.8 \pm 22.9^{b c}$ & $230.5 \pm 3.2^{\mathrm{c}}$ \\
\hline Femur & $284.2 \pm 64.2$ & $274.7 \pm 61.95$ & $272.0 \pm 29.5$ & $328.0 \pm 61.3$ & $250.3 \pm 52.8$ \\
\hline Hair $^{*}$ & 13.7 & 13.8 & 12.5 & 13.2 & 13.3 \\
\hline
\end{tabular}

*Identical quantities were collected from each animal and pooled in treatment groups; ${ }^{\dagger}$ Indicates significant difference between FA and HA groups; ${ }^{a, b}$ Different superscripts in the same row mean a significant difference at $\mathrm{P}<0.05$ level

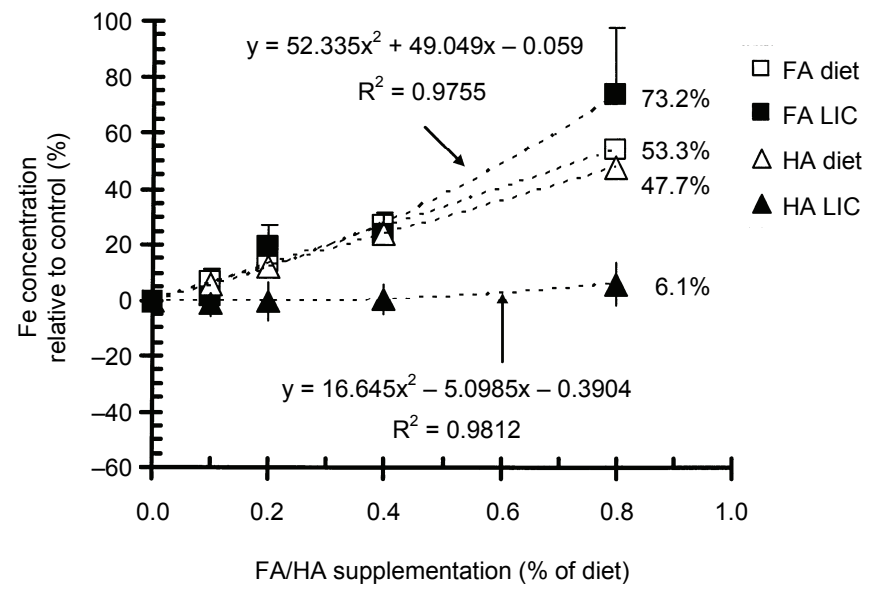

Fig. 1. Effect of fulvic acid (FA) or humic acid (HA) supplementation on the Fe concentration of diets and large intestinal contents (LIC)

These results are in agreement with the findings of Yeung et al. (2005) since in their experiment iron absorption decreased significantly in rats fed either high levels of inorganic $\left(\mathrm{FeSO}_{4}\right)$ or chelated (NaFeEDTA) forms, suggesting that 
rats adapted to high dietary iron concentration by down-regulating the absorption of iron. Dose-dependent responses were also observed in an acute iron toxicity study (Whittaker et al., 2002).

Because it was believed that the absorption of HA from the intestine is poor (1-5\%) (Islam et al., 2005) and the binding between Fe and HA is tight (Davies et al., 1997), we hypothesised that the HA-Fe complex would be absorbed poorly from the intestine. Contrary to this hypothesis, the Fe concentration in the large intestinal content of HA rats remained at the control level and did not follow the relative increment of Fe concentration of the diets, suggesting that the efficiency of iron absorption from the intestine increased with the dose of HA (Fig. 1) (at least $40 \%$ more iron absorption was noted), and up to $0.8 \%$ dietary HA supplementation a significant down-regulation of Fe absorption cannot be assumed.

Since the mechanism of absorption of HA-Fe is not clear, further investigations are needed to better understand this phenomenon. However, there is room for some speculations based on the suggestion of Pena-Méndez et al. (2005) in that given the mass spectra of humic acids the majority of the peaks were observed in the $\mathrm{m} / \mathrm{z}$ region of $100-1000 \mathrm{Da}$. It is possible that in an alkaline environment the molecular weight of HA-Fe is small enough to be absorbed from the intestinal tract. On the basis of these speculations we may assume that the relative changes of Fe concentration in the LIC are the consequence of the different efficiency of intestinal absorption.

The iron status of animals is presumably the most important physiological factor affecting iron absorption (Magnusson et al., 1981; Taylor et al., 1988; Lynch et al., 1989). Unlike many other nutrients, the body lacks a defined mechanism for the active excretion of iron, so body iron levels must be regulated at the level of absorption in the proximal small intestine (David and Anderson, 2005). The first step in the absorption process is the uptake of iron from the lumen of the intestine across the apical membrane into the enterocyte. The divalent metal transporter (DMT1) of brush border mediates this. DMT1 may be mediated by IRPs (iron regulatory proteins). The discovery of hepcidin (Nicolas et al., 2001), a protein that inhibits the iron absorption from the intestinal tract, placed the focus on the central role of liver in iron homeostasis.

Hepcidin is a small peptide synthesised by liver cells. It is a key regulator of iron homeostasis in mammals. Iron overload increases while anaemia decreases the hepatic production of hepcidin. These provide evidence of a negative feedback loop in which iron status regulates intestinal DMT1 expression, which in turn controls iron uptake. In isolated duodenal segments $200 \mathrm{nmol} / \mathrm{l}$ hepcidin induced a significant reduction in iron transport and DMT1 protein levels (Brasse-Lagnel et al., 2011). Iron not transferred to the body is incorporated into the iron storage molecule ferritin and is lost when the epithelial cell is ultimately sloughed at the villus tip. 
Summing up the results relating to the iron concentration change in LIC, Fig. 1 clearly shows that there is a statistically significant difference between the effect of FA and HA on iron absorption (Fe concentration of the LIC). FA turned out to be a good iron source but did not influence the relative rate of iron absorption; it paralleled with the Fe contents of the diets up to $52.7 \mathrm{mg} / \mathrm{kg}(0.4 \% \mathrm{FA}$ supplementation), while above this dietary Fe concentration, down-regulation of iron absorption was likely.

HA stimulated the relative rate of $\mathrm{Fe}$ absorption: up to $61.5 \mathrm{mg} / \mathrm{kg}$ dietary Fe concentration the iron content of the LIC was identical with the control level, suggesting that the extra iron added to the diets by the HA supplementation was quantitatively absorbed. There was no apparent down-regulation of iron absorption up to the investigated highest dietary Fe concentration.

An interesting question can be posed: where is the absorbed excess iron in the organism? Given that the liver is the main site of iron storage, the iron contents of the liver and the extrahepatic tissues may provide useful information regarding iron homeostasis.

Table 2 shows that in rats on FA-supplemented diets the iron content of the liver increased but not significantly over the control level, and there was also a mild but significant increase in the Fe content of the kidney relative to the control value.

The Fe concentration of the femur and hair was not different from that of the control. Therefore, we may assume that in the FA-supplemented rats the ironstoring capacity of the organism was saturated at and above $52.7 \mathrm{mg} / \mathrm{kg}$ dietary iron levels, and consequently the intestinal iron absorption was down-regulated.

Contrary to the FA-supplemented diets, HA treatment decreased the Fe concentration in the liver and kidney but not in the femur and hair (Table 2). There were significant differences between the liver and kidney Fe concentrations of FA and HA rats.

An explanation for the different effects of FA and HA on iron homeostasis may be that the binding of Fe to HA is much tighter than to FA (Davies et al., 1997). This is why HA did not provide iron either to the liver or to the other investigated organs. It is also possible that $\mathrm{HA}$ received $\mathrm{Fe}$ from the liver because of its strong free iron binding capacity. This speculation is aligned with the result of Yeung et al. (2005) that iron administered in the form of NaFeEDTA significantly decreased the iron content of the liver compared to $\mathrm{FeSO}_{4}$, although the same quantity of iron was absorbed from both Fe sources.

Although it is generally accepted that there is no urinary elimination of iron, Wareing et al. (2000) reported that the plasma iron can be included in the glomerular filtrate but most of it is reabsorbed by the loop of Henle. Further evidences for the possibility of urinary excretion of chelated iron or heavy metals are the successful treatment of beta thalassaemia with the orally administered chelator 1,2-dimethyl-3-hydroxypyrid-4-one, which is as effective as subcutane- 
ous desferrioxamine in increasing urinary iron excretion in patients loaded with iron (Kontoghiorghes et al., 1987), and that intravenous EDTA treatment resulted in a significant increase of urinary losses of lead, zinc, cadmium and calcium (Waters et al., 2001). In another study (Tandon et al., 1984) iron excretion in the urine increased within a 24-h period after injection with metal chelators (EDTA and DTPA). The treatment of patients diagnosed with heavy metal poisoning $(\mathrm{Pb}, \mathrm{Cd})$ also works along this line (Herzig et al., 1994; Zraly et al., 2008).

Because HA is also a good metal chelator, we speculate that the absorbed HA-Fe complex could have been eliminated from the organism by the kidney. This may lead to an iron deficient situation that can explain the lack of downregulation of iron absorption from the intestinal tract of HA-treated rats.

Although the exact mechanism(s) of the significantly different effects of FA and HA on iron absorption are still unknown, the most likely explanation is the different binding strength of HSs for Fe.

\section{Manganese}

Manganese is an essential trace element which is important for the normal metabolism of lipids, amino acids and carbohydrates, and has a significant function in several enzyme families. Approximately $1-5 \%$ of the ingested $\mathrm{Mn}$ is absorbed from the intestine (Aschner and Aschner, 2005). Although the specific mechanism of its absorption is not fully understood, it is believed that the site of Mn absorption is the small intestine, predominantly the duodenum (Moshtaghie et al., 2006). Manganese shares structural, biochemical and physiological functions with iron (Reid et al., 2006), and some evidence suggests that because these two elements are absorbed by the same transporter system (transferrin, Tf receptors, divalent metal transporter-1), there is a competition between $\mathrm{Mn}$ and $\mathrm{Fe}$ in the gastrointestinal tract (Gunshin et al., 1997). According to Aisen et al. (1969), within the plasma $\mathrm{Mn}$ is mainly attached to gamma-globulin and albumin, and a fraction of trivalent (3+) Mn is bound to transferrin. Manganese homeostasis is regulated by the liver (Papavasiliou et al., 1966; Klaasen, 1974); however, if the hepatic excretory route is blocked or overloading occurs, pancreatic excretion increases (Watts, 1990). Urinary Mn excretion is very low and independent of the intake (Yoshida et al., 2012). Because manganese is toxic in excessive amounts (Keen et al., 1994), the elimination of excess Mn from the organism is essential.

The effect of chelating agents on the biliary and urinary excretion of $\mathrm{Mn}$ is controversial; it was found to depend on the level of Mn loading and the type of chelates (Cikrt et al., 1987; Wieczorek and Oberdöster, 1989).

In this experiment, neither FA nor HA influenced the Mn content of the experimental diets significantly. Even at the highest supplementation level $(0.8 \%)$ the Mn concentration changes of the diets were negligible $(3.5 \%$ and $0.6 \%$, respectively) (Table 1). 
Table 3

Effect of fulvic acid (FA) or humic acid (HA) supplementation of diets on Mn concentration of the large intestinal content (LIC), liver, kidney, femur, and hair (mg/kg dry matter)

\begin{tabular}{|c|c|c|c|c|c|}
\hline & \multicolumn{5}{|c|}{ FA ( $\%$ of diet) } \\
\hline & 0.0 & 0.1 & 0.2 & 0.4 & 0.8 \\
\hline LIC & $262.0 \pm 46.6$ & $254.2 \pm 30.4$ & $262.8 \pm 17.8$ & $210.8 \pm 42.8$ & $243.2 \pm 42.8$ \\
\hline Liver & $8.88 \pm 0.44$ & $9.01 \pm 0.93$ & $9.70 \pm 0.81$ & $8.92 \pm 0.42$ & $8.84 \pm 0.97$ \\
\hline Kidney & $3.91 \pm 0.14$ & $3.90 \pm 0.23$ & $3.81 \pm 0.33$ & $3.86 \pm 0.26$ & $4.10 \pm 0.36$ \\
\hline Femur & $6.48 \pm 0.31$ & $6.56 \pm 0.53$ & $6.18 \pm 0.29$ & $5.67 \pm 0.22$ & $5.88 \pm 0.33$ \\
\hline \multirow[t]{3}{*}{ Hair $^{*}$} & 0.76 & 0.84 & 0.87 & 0.86 & 0.88 \\
\hline & \multicolumn{5}{|c|}{ HA ( $\%$ of diet $)$} \\
\hline & 0.0 & 0.1 & 0.2 & 0.4 & 0.8 \\
\hline LIC & $262.0 \pm 46.6^{\mathrm{a}}$ & $256.6 \pm 44.7^{\mathrm{a}}$ & $206.2 \pm 53.2^{\mathrm{ab}}$ & $218.4 \pm 22.6^{\mathrm{ab}}$ & $202.4 \pm 16.4^{b}$ \\
\hline Liver & $8.88 \pm 0.44$ & $9.52 \pm 0.68$ & $8.12 \pm 0.95$ & $8.81 \pm 0.26$ & $8.37 \pm 0.53$ \\
\hline Kidney & $3.91 \pm 0.14$ & $4.03 \pm 0.26$ & $3.91 \pm 0.11$ & $3.85 \pm 0.14$ & $3.91 \pm 0.29$ \\
\hline Femur & $6.48 \pm 0.36$ & $5.77 \pm 0.52$ & $5.80 \pm 0.32$ & $6.37 \pm 0.29$ & $6.03 \pm 0.33$ \\
\hline Hair $^{*}$ & 0.76 & 0.85 & 0.82 & 0.81 & 0.83 \\
\hline
\end{tabular}

* Identical quantities were collected from each animal and pooled in treatment groups; ${ }^{\mathrm{a}, \mathrm{b}}$ Different superscripts in the same row mean a significant difference at $\mathrm{P}<0.05$ level

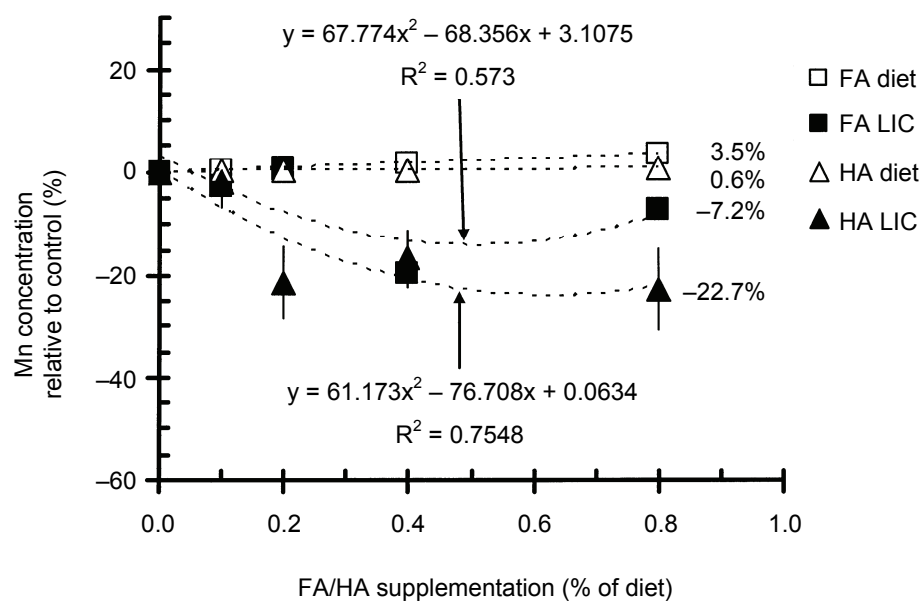

Fig. 2. Effect of fulvic acid (FA) or humic acid (HA) supplementation on the Mn concentration of diets and large intestinal contents (LIC)

Table 3 indicates the changes of Mn concentrations in the LIC, liver, kidney, femur, and hair. None of the tested FA supplementation rates influenced significantly the Mn concentrations of the LIC; however, the Mn concentration 
of the LIC was always lower in the FA-supplemented than in the control animals $(-7.2 \%$ as compared to the control) (Fig. 2, Table 3). The same results can be seen at $0.1,0.2$ and $0.4 \%$ HA supplementation levels; however, the $0.8 \%$ dietary HA level significantly decreased the Mn concentration of the LIC $(-22.7 \%)$. We could see a weak dose-related effect of HA; however, statistically this was not significant (Table 3).

The changes of Mn concentrations in the LIC provide only indirect information about the actual balance of Mn absorption and excretion; however, it is clear that the balance of absorption and excretion is positive, more Mn was absorbed in the treatment groups than in the control, at least in the case of rats fed HA-supplemented diets. Neither FA nor HA supplementation of the diets influenced the Mn concentrations of the liver, kidney and femur significantly. The Mn content of the hair samples was consistently higher than the control value in both the FA- and the HA-treated rats; however, without a statistical analysis, due to the determination made in pooled samples, this result is not conclusive (Table 3).

\section{Conclusions}

Finally, on the basis of the results of this experiment the following conclusions can be drawn: (1) The effects of FA and HA on iron homeostasis were significantly different. (2) FA proved to be a good iron source; its absorption paralleled with the $\mathrm{Fe}$ contents of the diets up to $52.7 \mathrm{mg} / \mathrm{kg}$ ( $0.4 \%$ FA supplementation), but above this level, a down-regulation of Fe absorption can be assumed. (3) The slight increase of Fe concentration in the liver of FA-supplemented rats was not significant. (4) The Fe concentrations of the kidney were significantly higher than in the control rats at all FA supplemental levels. (5) HA significantly stimulated the iron absorption and there was no down-regulation of Fe absorption up to $0.8 \%$ HA supplementation level (61.5 mg Fe/kg diet). (6) Despite the noted absorption of the HA-Fe complex, the iron contents of the liver and kidney of the rats decreased significantly, suggesting that HA is not a good iron source and in case of parenteral administration it can be a good tool in the treatment of beta thalassaemia or heavy metal toxicities. (7) Neither FA nor HA supplementation influenced the Fe contents of the femur and hair. (8) Both FA and HA decreased the Mn concentration in the LIC but this effect was significant only at the $0.8 \%$ HA supplementation level (-22.7\%). (9) Neither FA nor HA influenced significantly the manganese concentrations of the liver, kidney and femur. (10) The Mn concentration of the hair was higher in rats fed FA- and HAsupplemented diets than in the control; however, this result needs further confirmation. 


\section{Acknowledgement}

This study was sponsored by the Hungarian Scientific Research Fund (OTKA T049116). This research was supported by the 11475-4/2016/FEKUT grant of the Hungarian Ministry of Human Resources.

\section{References}

Aisen, P., Aasa, R. and Redfield, A. G. (1969): The chromium, manganese, and cobalt complexes of transferrin. J. Biol. Chem. 244, 4628-4633.

Aschner, J. and Aschner, M. (2005): Nutritional aspects of manganese homeostasis. Mol. Aspects Med. 26, 353-362.

Bailey, C. A., White, K. E. and Donke, S. L. (1996): Evaluation of menefee humate on the performance of broilers. Poultry Sci. 75 (Suppl. 1), 84. (Abstr.)

Boyd, S. A., Sommers, L. E., Nelson, D. W. and West, D. X. (1981): The mechanism of copper (II) binding by humic acid: an electron spin resonance study of a copper (II)-humic acid complex and some adducts with nitrogen donors. Soil Sci. Soc. Am. J. 45, 745-749.

Brasse-Lagnel, C., Karim, Z., Peterson, P., Berki, S., Bado, A. and Beamont, C. (2011): Intestinal DMT1 cotransporter is down-regulated by hepcidin via proteasome internalization and degradation. Gastroenterology 140, 1261-1271.

Cagin, Y. F., Sahin, N., Erdogan, M. A., Atayan, Y., Eyol, E., Bilgic, Y., Seckin, Y. and Colak, C. (2016): The acute effect of humic acid on iron accumulation in rats. Biol. Trace Elem. Res. 171, 145-155.

Cikrt, M., Lepsi, P., Lukás, E., Sperlingová, I., Horáková, L. and Jones, M. M. (1987): The effect of some chelating agents on the biliary and urinary excretion of manganese in rats. J. Hyg. Epidemiol. Microbiol. Immunol. 31, 31-37.

David, M. F. and Anderson, G. J. (2005): Iron imports. I. Intestinal iron absorption and its regulation. Am. J. Physiol. Gastrointest. Liver Physiol. 289, 631-635.

Davies, G., Fataftah, A., Cherkassky, A., Ghabour, E. A., Radwan, A., Jansen, S. A., Kolla, S., Paciolla, M. D., Stein, L. T. Jr., Buermann, W., Balasubramanian, M., Budnick, J. and Xinga, B. (1997): Tight metal binding by humic acids and its role in biomineralization. J. Chem. Soc. Dalton Trans 21, 4047-4060.

Fischer, J. G., Glauert, H. P., Yin, T., Sweeney-Reeves, M. L., Larmonier, N. and Black, M. C. (2002): Moderate iron overload enhances lipid peroxidation in livers of rats, but does not effect NF-kappaB activation induced by the peroxisome poliferator, Wy-14, 643. J. Nutr. 132, 2525-2531.

Gunshin, H., Mackenzie, B., Berger, U. V., Gunshin, Y., Romero, M. F., Boron, W. F., Nussberger, W. F., Golan, J. L. and Hediger, M. A. (1997): Cloning and characterization of a mammalian proton-coupled metal-ion transporter. Nature 338, 482-488.

Herzig, I., Hampl, J., Docekalova, V. A., Psarkova, B. and Vicek, J. V. (1994): The effect of sodium huminate on cadmium deposition in the organs of chickens. Vet. Med.-Czech 39, $175-185$.

Herzig, I., Navratilova, J., Totusek, J., Suchy, P. and Vecerek, V. (2009): The effect of humic acid on zinc accumulation in chicken broiler tissues. Czech J. Anim. Sci. 54, 121-127.

Islam, K. M. S., Schumacher, A. and Gropp, J. M. (2005): Humic acid substances in animal agriculture. Pakistan J. Nutr. 4, 126-134.

Kaya, C. A. and Tuncer, S. D. (2009): The effects of humates on fattening performance, carcass quality and some blood parameters of broilers. J. Anim. Vet. Adv. 8, 281-284. 
Keen, C. L., Zidenberg-Cherr, S. and Lonnerdal, B. (1994): Nutritional and toxicological aspects of manganase intake: an overview. In: Mertz, W., Abernathy, C. O. and Olin, S. S. (eds) Risk Assessment of Essential Elements. ILSI, Washington, D.C. pp. 221-235.

Klaasen, C. D. (1974): Biliary excretion of manganese in rats, rabbits, and dogs. Toxicol. Appl. Pharm. 29, 458-468.

Kocabagli, N., Alp, M., Acar, N. and Kahraman, R. (2002): The effects of dietary humate supplementation on broiler growth and carcass yield. Poultry Sci. 81, 227-230.

Kontoghiorghes, G. J., Aldouri, M. A., Hoffbrand, A. V., Barr, J., Wonke, B., Kourouclaris, T. and Sheppard, L. (1987): Effective chelation of iron in beta thalassaemia with the oral chelator 1,2-dimethyl-3-hydroxypyrid-4-one. Brit. Med. J. 295, 1509-1512.

Livens, F. R. (1991): Chemical reactions of metals with humic material. Environ. Pollut. 70, 183-208.

Lynch, S. R., Skikne, B. S. and Cook, J. D. (1989): Food iron absorption in idiopathic hemochromatosis. Blood 74, 2187-2193.

Madronova, L., Kozler, J., Cezikova, J., Novak, J. and Janos, P. (2001): Humic acids from coal of the North-Bohemia coal field. III. Metal binding properties of humic acids - measurements in a column arrangement. React. Funct. Polym. 47, 119-123.

Magnusson, B., Bjorn-Rasmussen, E., Hallberg, L. and Rossander, L. (1981): Iron absorption in relation to iron status. Scand J. Haematol. 27, 201-208.

Mevlüt, K., Macit, M., Esenbuga, N., Durdag, H., Turgut, L. and Bilgin, Ö. C. (2004): Effect of supplemental humate at different levels on growth performance, slaughter and carcass traits of broilers. Int. J. Poultry Sci. 3, 406-410.

Miret, S., Simpson, R. J. and McKie, A. T. (2003): Physiology and molecular biology of dietary iron absorption. Annu. Rev. Nutr. 23, 283-301.

Morgan, E. H. and Oates, P. S. (2002): Mechanism and regulation of intestinal iron absorption. Blood Cells Mol. Dis. 29, 384-399.

Moshtaghie, A. A., Badii, A. A. and Hassanzadeh, T. (2006): Investigation of manganese and iron absorption by rat everted gut sac. Pakistan J. Biol. Sci. 9, 1346-1349.

Neuendorf, K. K. E., Mehl, J. P. and Jackson, J. A. (2011): Glossary of Geology. Fifth edition, revised. American Geosciences Institute, Alexandria, VA, USA. 800 pp.

Nicolas, G., Bennoun, M., Devaux, I., Beaumont, C., Grandchamp, B., Kahn, A. and Vaulont, S. (2001): Lack of hepcidin gene expression and severe tissue iron overload in upstream stimulatory factor 2 (USF2) knockout mice. Proc. Natl Acad. Sci. USA 98, 8780-8785.

NRC (1995): Nutrient Requirements of Laboratory Animals. Fourth revised edition. National Academy Press, Washington, D.C.

Papavasiliou, P. S., Miller, S. T. and Cotzias, G. C. (1966): Role of liver in regulating distribution and excretion of manganese. Am. J. Physiol. 211, 211-216.

Parks, C. W. (1998): The use of Menefee Humate ${ }^{\mathrm{TM}}$ in typical and low-crude protein diets for turkey toms and in the bioremeditation of petroleum contaminated soil amended with poultry litter as a co-substrate and nutrient source. Master's Thesis. North Carolina State University, Raleigh, NC, USA.

Pena-Méndez, E. M., Havel, J. and Patocka, J. (2005): Humic substances - compounds of still unknown structure: application in agriculture, industry, environment, and biomedicine. J. Appl. Biomed. 3, 13-24.

Reeves, P. G. (1997): Components of the AIN-93 diets as improvements in the AIN-76A rodent diet. J. Nutr. 127, 838S-841S.

Reid, S. D., Blacke, A. J., Wilson, C. and Love, B. J. (2006): Syntheses and structures of dinuclear double-stranded helicates of divalent manganese, iron cobalt, and zinc. Inorg. Chem. $\mathbf{4 5 ,}$ 636-643.

Schuhmacher, A. and Gropp, J. M. (2000): Effect of humic acids on health state and performance of weaners. Proc. Soc. Nutr. Physiol. 9, 77.

Stevenson, F. J. (1994): Humus Chemistry: Genesis, Composition, Reactions. John Wiley \& Sons Inc., New York. 
Takeuchi, K., Bjarnason, I., Laftah, A. H., Latunde-Dada, G. O., Simpson, R. J. and McKie, A. T. (2005): Expression of iron absorption genes in mouse large intestine. Scand. J. Gastroenterol. 40, 169-177.

Tandon, S. K., Jain, V. K. and Mathur, A. K. (1984): Effect of metal chelators on excretion and tissue levels of essential trace elements. Environ. Res. 35, 237-245.

Taylor, P., Martinez-Torres, C., Leeds, I., Ramirez, J., Garcia-Casal, M. N. and Layrisse, M. (1988): Relationships among iron absorption, percent saturation of plasma transferrin and serum ferritin concentration in humans. J. Nutr. 118, 1110-1115.

Wareing, M., Ferguson, C. J., Green, R., Riccardi, D. and Smith, C. P. (2000): In vivo characterisation of renal iron transport in the anaesthetized rats. J. Physiol. 524, 581-586.

Waters, R. S., Bryden, N. A., Patterson, K. Y., Veillon, C. and Anderson, R. A. (2001): EDTA chelation effects on urinary losses of cadmium, chromium, cobalt, copper, lead, magnesium, and zinc. Biol. Trace Elem. Res. 83, 207-221.

Watts, D. L. (1990): The nutritional relationships of manganese. J. Orthomol. Med. 5, 219-222.

Whittaker, P., Ali, S. F., Imam, S. Z. and Dunkel, V. C. (2002): Acute toxicity of carbonyl iron and sodium iron EDTA compared with ferrous sulphate in young rats. Regul. Toxicol. Pharm. 36, 280-286.

Wieczorek, H. and Oberdöster, G. (1989): Effect of selected chelating agents on organ distribution and excretion of manganese after inhalation exposure to $54 \mathrm{MnCl}_{2}$. I. Injection of chelating agents. Pol. J. Occup. Med. 2, 261-267.

Willis, K. (2015): An investigation of the effects of fulvic and humic acids on the absorption of selected drugs, vitamins and minerals using the everted mouse gut model. Submitted in fulfilment of the requirements for the degree Magister Scientiae in Pharmacology, in the Department of Pharmacology, Faculty of Health Sciences, University of Pretoria. http://repository.up.ac.za/bitstream/handle/2263/46044/Willis_Investigation_2015.pdf?seq uence $=1 \&$ isAllowed $=y$

Yeung, C. K., Zhu, L., Glahn, R. P. and Miller, D. D. (2005): Tissue iron distribution and adaptation of iron absorption in rats exposed to high dietary level of NaFeEDTA. J. Agr. Food Chem. 53, 8087-8091.

Yoshida, M., Fukuwatari, T., Sakai, J., Tsuji, T. and Shibata, K. (2012): Correlation between mineral intake and urinary excretion in free-living Japanese young women. Food Nutr. Sci. 3, $123-128$.

Zraly, Z. and Pisarikova, B. (2010): Effect of sodium humate on the content of trace elements in organs of weaned piglets. Acta Vet. Brno 79, 73-79.

Zraly, Z., Pisarikova, B., Trcková, M. and Navrátilová, M. (2008): Effect of humic acids on lead accumulation in chicken organs and muscles. Acta Vet. Brno 77, 439-445. 